\title{
Unusual spinal needle defect: projecting stylet
}

\author{
Rosie Earle, MD (D) - Dannielle Tinker, MD • \\ Himat Vaghadia, MBBS, FRCPC
}

Received: 26 October 2018/Revised: 27 October 2018/Accepted: 29 October 2018/Published online: 11 March 2019

(C) Canadian Anesthesiologists' Society 2019

\section{To the Editor,}

The modern version of a Quincke-type spinal needle was developed in 1914 after Bainbridge had described his spinal needle with a cutting bevel and matching beveled stylet in $1900 .{ }^{1}$ Reports of spinal needle defects in the literature seem to be rare. Previous authors have described an unusual spinal needle mid-shaft micro-tear with resultant efflux of local anesthetic. ${ }^{2}$ Another group reported a $180^{\circ}$ malrotation of the stylet bevel so that it faced the needle and resulted in a forked tip, which prevented puncture of the skin. ${ }^{3}$ We report an unusual spinal needle defect that pertains to an abnormal $6 \mathrm{~mm}$ projection of the stylet beyond the bevel in a disposable spinal needle.

Recently, we attempted to use a disposable single-use 22G Quincke needle (model 405181; $0.7 \mathrm{~mm} \times 90 \mathrm{~mm}$; Becton Dickinson, Franklin Lakes, NJ, USA) to conduct spinal anesthesia in an elderly patient. We encountered significant resistance when puncturing the skin with the spinal needle; examination revealed that the stylet was projecting approximately $6 \mathrm{~mm}$ beyond the needle bevel (Figure). A replacement needle of the same model was inspected and found to be normal, and the procedure was completed without complication.

There is a previous report of a re-useable spinal needle (same manufacturer) where the stylet projected $2 \mathrm{~mm}$ beyond the spinal needle bevel and became kinked at the

\footnotetext{
R. Earle, MD $(\bowtie) \cdot D$. Tinker, MD .

H. Vaghadia, MBBS, FRCPC

Department of Anaesthesia, Vancouver Coastal Health,

Vancouver, BC, Canada

e-mail: earle.rk@gmail.com
}

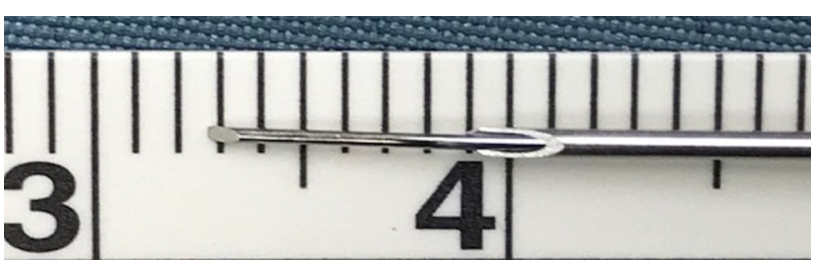

FIGURE Image of disposable single-use 22G Quincke needle (model 405181; $0.7 \mathrm{~mm} \times 90 \mathrm{~mm}$; Becton Dickinson, Franklin Lakes, USA) demonstrating its integrated stylet projecting $6 \mathrm{~mm}$ beyond the needle's beveled tip

heel of the bevel during insertion. ${ }^{4}$ In that case, the stylet projection beyond the needle's beveled tip was not noted during insertion and difficulty was only encountered when the stylet was removed. The stylet had kinked after needle insertion and significant force was needed to dislodge it from the patient's back.

Failure to identify these types of defects prior to needle insertion pose risks of stylet deformity and difficulty with removal. Theoretically, if the stylet tip were sheared or broken, then a foreign body may remain inside the patient. Based on this experience and previous reports of similar defects, we recommend that the needle tip be examined as part of an equipment checklist prior to spinal anesthesia.

Conflict of interest None declared.

Editorial responsibility This submission was handled by Dr. Hilary P. Grocott, Editor-in-Chief, Canadian Journal of Anesthesia.

Funding This work was supported by Internal Departmental Funds. 


\section{References}

1. Calthorpe $N$. The history of spinal needles: getting to the point. Anaesthesia 2004; 59: 1231-41.

2. Adley R, Geraghty IF. Defective spinal needle. Anaesthesia 1991; 26: $159-60$

3. Singh $S$. Defective spinal needle: Failure in piercing the skin during lumbar puncture. J Anaesthesiol Clin Pharmacol 2011; 27: $131-2$.
4. Sharma $P$, Singh B, Manocha A. Stylet stuck in the back: an unusual complication of spinal needle. Anesth Analg 2005; 101: 296-7.

Publisher's Note Springer Nature remains neutral with regard to jurisdictional claims in published maps and institutional affiliations. 